\title{
Crop Physiology and Productivity: The Iraqi Experience
}

\author{
Khudhair Abbas Jaddoa \\ College of Agriculture, University of Baghdad, Baghdad, Iraq
}

Email address:

khdhayerjaddoa@yahoo.com

\section{To cite this article:}

Khudhair Abbas Jaddoa. Crop Physiology and Productivity: The Iraqi Experience. International Journal of Applied Agricultural Sciences. Vol. 1, No. 3, 2015, pp. 74-78. doi: 10.11648/j.ijaas.20150103.15

\begin{abstract}
Understanding crop physiology provides us with an exciting information and knowledge for better crop management towards increasing productivity. Based on this fact, many physiological aspects of cereal crops (wheat, rice, sorghum and barley) have been studied during the last two decades in Iraq with interesting achievements. These aspects included : physiological aspects of tillering in wheat and its relationship to the crop management and grain yield, seed priming of rice and sorghum for better seed germination and field establishment, accurate timing of agrochemicals application (e.g. nitrogen fertilizer and plant growth regulators) based on certain critical growth stages to increase grain yield of wheat and barley, and proposed strategies for saving water in rice cultivation among them growing rice successfully, under sprinkler irrigation for saving water and increasing water use efficiency (WUE). The objective of these four case studies was to improve the cereals management and, hence, increasing their grain yield via physiological approaches. Considerable increases in the grain yield of these cereals crops have been achieved via the combination of crop physiology and crop management. Full details of the methodologies and achievements will be presented for each case study. In conclusion, this approach, may represents a good and effective strategy to increase crop productivity and saving water.
\end{abstract}

Keywords: Crop Physiology, Crop Productivity, Crop Management, Seed Priming, Water Use Efficiency

\section{Introduction}

Crop physiology is the science of plant's functions under normal and stressed conditions. Like any other area in biological sciences, both the scope and depth of our knowledge of crop physiology are rapidly expanding as crop physiologists are continuously making new discoveries. This phenomenon has resulted in the compilations of a large volume of information since the first establishment of crop physiology as a science. This led to the fact that physiological processes control plant growth and crop yield. Therefore, better, comprehensive and up-dated understanding of crop performance in relation to the yield becomes essential as yield is the ultimate gain of all physiological processes. In fact, this makes physiological studies very effective and successful approach to solve the problems of crop productivity. In Iraq, during the last two decades, many physiological studies were conducted aiming to increase the cereal crop productivity via improving the crop management. Four case studies will be presented include : relationship between tillering and crop management of wheat, seed priming of rice and sorghum for better seed germination and field establishment, rice and water requirement and accurate timing of agrochemical application for barley and wheat.

\section{Methodologies and Achievements}

\subsection{Relationship Between Tillering and Crop Management of Wheat}

Tillering is a characteristics of cereals (e.g. wheat) as it is the longest process in the wheat life cycle and the most important growth stages where most grain yield components are determinant during tillering. Based on these facts, a comprehensive studies of tillering aspects of wheat under my supervision as influenced by genotypes, sowing date, nitrogen level, seeding rates and seeding depth were conducted in Iraq during the period (2007-2011) (Al-Hassan 2007, 2011, Baqir, 2011).

The objectives of these studies were to obtain better understanding of tillering pattern and capacity of different wheat varieties under the influence of many agronomics practices in an attempt to relate tillering process to the wheat management. The effect of seeding rates and nitrogen levels on tillering will be presented as they are key factors of crop management. Four wheat varieties (Al-Iraq, Al-Fath, AbuGhraib -3 and Iba - 99) were grown by using five seeding rates $\left(60,80,100,120\right.$ and $\left.140 \mathrm{~kg} \cdot \mathrm{ha}^{-1}\right)$ and five nitrogen 
levels $\left(0,100,150,200\right.$ and $\left.250 \mathrm{~kg} \cdot \mathrm{ha}^{-1}\right)$ in two seasons (2008-2009) and (2009-1010) (Al-Hassan, 2011). Results showed that wheat varieties were significantly different in their tiller numbers. ${ }^{-1}$ plant in both seasons as affected by seeding rates and $\mathrm{N}$ levels. Al-Iraq variety had the highest averages of tiller number and grain yield in both seasons. The seeding rate $\left(100 \mathrm{~kg} \cdot \mathrm{ha}^{-1}\right)$ and $\mathrm{N}$ level $\left(150 \mathrm{~kg} \cdot \mathrm{ha}^{-1}\right)$ gave the highest grain yield.ha ${ }^{-1}$. Results also indicated that tiller number. ${ }^{-1}$ Plant decreased by increasing seeding rate but increased by increasing $\mathrm{N}$ level up to $200 \mathrm{~kg} \cdot \mathrm{ha}^{-1}$ then a significant reduction in tiller number occurred when using $250 \mathrm{~kg} \cdot \mathrm{ha}^{-1}$. Therefore, seeding rate and $\mathrm{N}$ fertilizer should be based on the tillering capacity of each variety.

Results of this study recommended $100 \mathrm{~kg} \cdot \mathrm{ha}^{-1}$ seeding rate and $150 \mathrm{~kg} \cdot \mathrm{ha}^{-1}$ nitrogen for Al-Iraq and Abu-Ghraib 3 varieties while for Al-Fath and Iba-99 varieties the recommendation was $120 \mathrm{~kg} \cdot \mathrm{ha}^{-1}$ seeding rate and $200 \mathrm{~kg} \cdot \mathrm{ha}^{-}$ ${ }^{1}$ nitrogen.

\subsection{Seed Priming of Rice and Sorghum for Better Seed Germination and Field Establishment}

Seed priming is a generic technology and addresses a fundamental requirement for crop production - the need to have a field full of vigorous plants. It is a simple, proven technology that has been developed, tested and refined in laboratories, in experimental plots, and by farmers themselves in their fields. It is easy to use with a wide range of crops in many different farming conditions. Seed priming can be accomplished through different methods such as hydro-priming (soaking in water), Osmo-priming (soaking in osmotic solutions such as polyethylene glycol, potassium salts, e.g. $\mathrm{KCl}, \mathrm{K}_{2} \mathrm{SO}_{4}$ ), vitamin, e.g. ascorbic acid and plant growth regulators $\left(\mathrm{GA}_{3}, \mathrm{CCC}\right.$, Ethephon, IAA). Primed seeds usually have higher and early synchronized germination (Brocklehurst et al., 1984, Kaya et al., 2006, Farooq et al., 2009) due to simply a reduction in the lag time of imbibition (Brocklehurst and Dearman, 2008), build - up of germination - enhancing metabolites (Farooq et al., 2006), metabolic repair during imbibition (Bray et al., 1989) and osmotic adjustment (Bradford, 1986). Another benefits of seed priming have been reported e.g. better competition with weeds, early flowering and maturity and resistance to environmental stresses such as drought and salinity (Alireza EIVAZi 2012), and Farooq et al., 2013.

In Iraq, rice and sorghum grown widely as important summer crops. However, cultivation of these crops facing the problem of low germination and field emergence in rice grown by direct dry drilling and the high gap between standard germination percentage and field emergence in sorghum. Therefore, a study was conducted during $2006-$ 2009 to solve these problems via seed priming technique under my supervision (Cheyad, 2008, Al-Selawy, 2011).

\subsubsection{Rice Study}

Seeds of three varieties (Anber -33, Yasamin and Furat-1) were soaked in the solutions of GA3 (300, 600, and 900 $\left.\mathrm{mg} . \mathrm{L}^{-1}\right), \mathrm{KCl}\left(10\right.$ and $\left.20 \mathrm{mg} \cdot \mathrm{L}^{-1}\right)$ and Ascorbic acid $(10,20$ and $\left.30 \mathrm{mg} . \mathrm{L}^{-1}\right)$ besides two control treatments: uncooked seeds (dry seeds) and soaked seeds with water only. Primed seeds were grown by using direct dry drilling method in two seasons 2008 and 2009.

The results indicated that soaked seeds with GA3 (300 $\left.\mathrm{mg} . \mathrm{L}^{-1}\right)$ significantly increased the field emergence percentage from 59.55 and 60.73 (un soaked seed) to the 71.53 and $76.51 \%$ in 2008 and 2009 seasons, respectively.(Fig. 1). This improvement in the field emergence was translated in the significant increase in the grain yield from 4.47 and 4.71 for un-soaked seeds to the 6.16 and 6.31 t.ha $^{-1}$ ) for $\mathrm{GA}_{3}$ soaked seeds in both seasons, respectively.

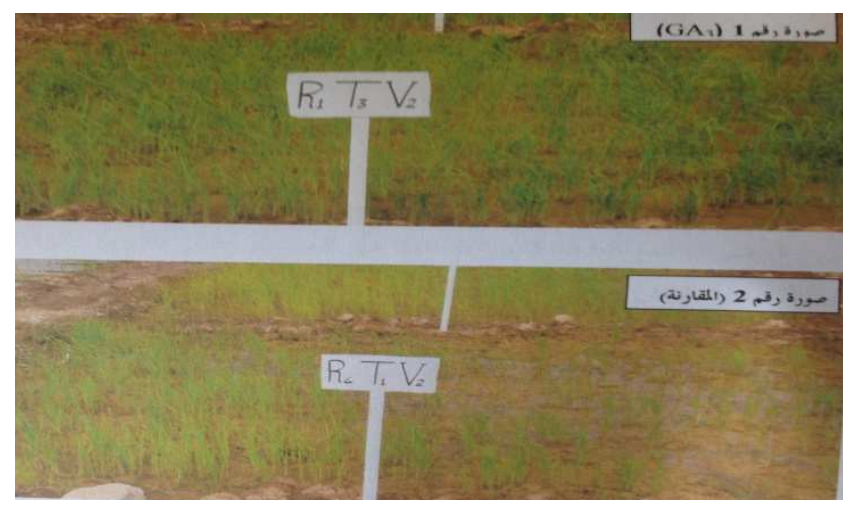

Fig. 1. Effect of $\mathrm{GA}_{3}$ on field emergence of rice (above) compared with control (below).

In conclusion, rice seed priming, in general, increased standard germination percentage, field emergence, seedlings growth and grain yield.

\subsubsection{Sorghum Study}

Seeds of variety Inqath were soaked with GA3 (100, 200 and $300 \mathrm{mg} . \mathrm{L}^{-1}$ ) for $24 \mathrm{hrs}$. and grown in the spring season of 2006. Results indicated that GA3 (300 mg. $\left.\mathrm{L}^{-1}\right)$ significantly increased the standard germination percentage from 65.25 for un-soaked seeds to the $73.89 \%$. Field emergence percentage also increased from 52.08 for un-soaked seeds to the $57.5 \%$ by GA3 (200 mg.L $\left.\mathrm{L}^{-1}\right)$ with no significant difference between GA3 (200 mg. $\left.\mathrm{L}^{-1}\right)$ and GA3 (300 mg. $\left.\mathrm{L}^{-1}\right)$. Seedlings characteristics (radicle length, plumule length and dry weight) were significantly increased by GA3 (300 mg. $\left.\mathrm{L}^{-1}\right)$.

\subsection{Rice and Water Requirements}

The future of rice cultivation and production in Iraq and elsewhere will depend entirely on the development of new technologies to use water efficiently i.e. more rice per unit of water or more crop per water drop to maximize the productivity of water unit not area unit. The new directions, currently are to develop efficient management policies in operating irrigation systems, adopting new technologies to reduce rice water consumption and making changes in the rice plants themselves that make them using water efficiently to prevent or reduce the rice field flooding. These strategies are so important as rice crop is the biggest consumer of water: it takes some 5.000 liters of water to produce one kilogram of 
rice. Compared with other crops, rice production is less efficient in the way it use water. Wheat, for example, consumes only $4.000 \mathrm{~m}^{3} \cdot \mathrm{ha}^{-1}$ while rice consumes 7.650 $\mathrm{m}^{3} \cdot \mathrm{ha}^{-1}$ (IRRI, 1994-1995).

\subsubsection{Growing Rice Under Sprinkler Irrigation}

Many field trails were conducted during the period (20012004) by growing rice variety Anber -33 under sprinkler irrigation for $4 \mathrm{hrs}$. Daily operation of sprinkler irrigation. (Fig. 2)

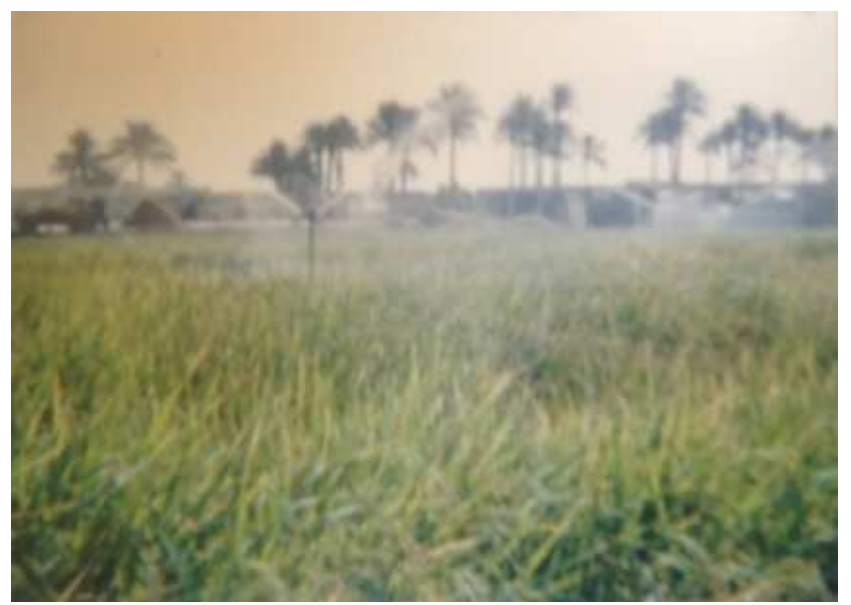

Fig. 2. Growing rice under sprinkler irrigation.

This method saved more water compared with the submerge irrigation without significant reduction in the grain yield i.e. the quantity of applied water by using sprinkler irrigation for $4 \mathrm{hrs}$. was $28 \mathrm{~mm}$ with grain yield 3453.13 kg.ha ${ }^{-1}$ compared with $80-100 \mathrm{~mm}$ daily by using submerge irrigation with grain yield $3589.20 \mathrm{~kg} \cdot \mathrm{ha}^{-1}$ (Al-Mashhadani, 2003). Similar results have been achieved by Salih et al., 2007 by growing three rice cultivars under sprinkler irrigation. The irrigation was given at three scheduling, every day, every two days and every three days with the daily operation time 2, 4, $6 \mathrm{hrs}$, respectively. The overall average of grain yield under sprinkler irrigation was $4.7 \mathrm{t}^{\mathrm{h}} \mathrm{ha}^{-1}$ while the total amount of water used under sprinkler irrigation was 22500 and $18600 \mathrm{~m}^{3} \cdot \mathrm{ha}^{-1}$ for two seasons 2002 and 2004, respectively compared with $70.000 \mathrm{~m}^{3} \cdot \mathrm{ha}^{-1}$ by using submerge irrigation method (Salih et al., 1999). This means a huge saving of water was obtained by using sprinkler irrigation. Interesting results that water use efficiency WUE was high under sprinkler irrigation i.e. 0.250 and $0.200 \mathrm{~kg} . \mathrm{m}^{-}$ ${ }^{3}$ for both seasons, respectively compared with $0.050 \mathrm{~kg} . \mathrm{m}^{-1}$ under submerge irrigation in previous study (Salih et al., 1999).

\subsubsection{Breeding Rice Cultivars with Less Water Requirements and High WUE}

Over 5 years (1997-2001) of conducting field trials and on-farm research, a new rice cultivar was tested, evaluated and released in 2001 (Fig. 3). This variety was watered by using intermittent irrigation method (i.e. deficit irrigation) every 7 days. Grain yield (GY) t.ha-1, total consumed water (TCW) m3.ha-1 and water use efficiency WUE (1 kg grain.m-3 water) of this new variety when irrigated every 7 days is given in Table (1).

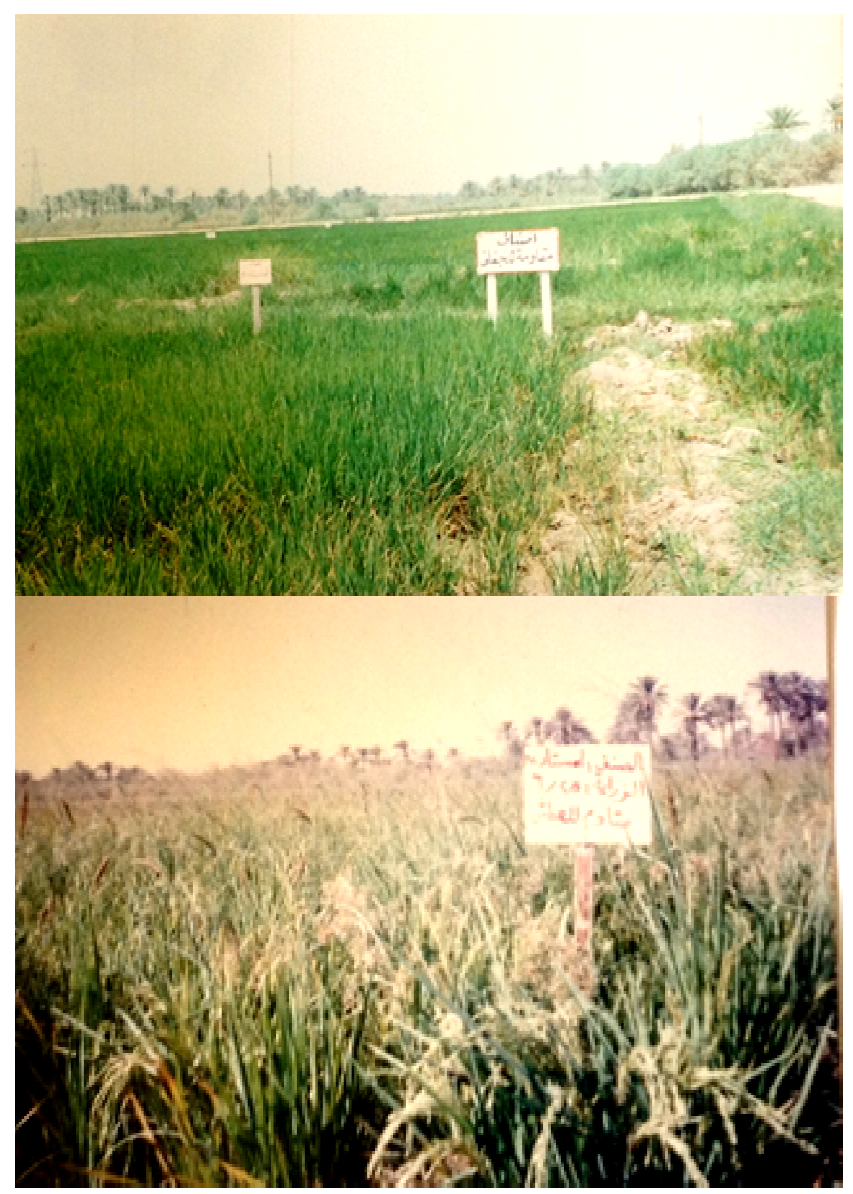

Fig. 3. AL- SOMOOD (DROUGHT TOLERANCE VARIETY) at different growth stages.

Table 1. GY, TCW and WUE of Al-Somood variety grown in two seasons.

\begin{tabular}{lllll}
\hline Season & Irrigation ethod & GY & TCW & WUE \\
\hline \multirow{2}{*}{1997} & Submerge & 10.64 & 108550 & 0.098 \\
& Every 7 days & 7.20 & 30527 & 0.236 \\
\multirow{2}{*}{1998} & Submerge & 5.95 & 95630 & 0.062 \\
& Every 7 days & 5.71 & 29443 & 0.194 \\
\multirow{2}{*}{ Mean } & Submerge & 8.29 & 102090 & 0.080 \\
& Every 7 days & 6.45 & 29985 & 0.215 \\
\hline
\end{tabular}

Although there was a reduction in the grain yield by $(22 \%)$ when crop irrigated every 7 days, a huge reduction in the TCW by $(70 \%)$ was achieved. However, the WUE was increased by $(168 \%)$. This variety was characterized by its short growth duration (135) days, and short plant height (80) $\mathrm{cm}$ as an average compared with (155) and (130) for the local variety anber-33. Interesting results here, that the huge saving in TCW will be used in growing new land by rice or other summer crop e.g. maize which compensates for the reduction in GY of rice due to the intermittent irrigation (every 7 days). Additional benefits could be gained by using this method of irrigation among them: reduction in the contamination of environment via less amounts of 
agrochemical which used in cultivation of rice (fungicides, fertilizers, herbicides, etc.) to be moved to the drainage and irrigation channels. Therefore, human being, animals, birds and fishes will be protected from the chemical poising risks.

\subsubsection{Breeding Rice Varieties for Short Growth Duration}

Breeding for short growth duration is considered one of the new directions in the field of plant breeding as short growth duration variety consumes less water. After 5 years of trialing, a new variety called Bernamaj-4 was released. (Fig. 4). Characteristics of this variety compared with local one and other genotype are given in Table (2).

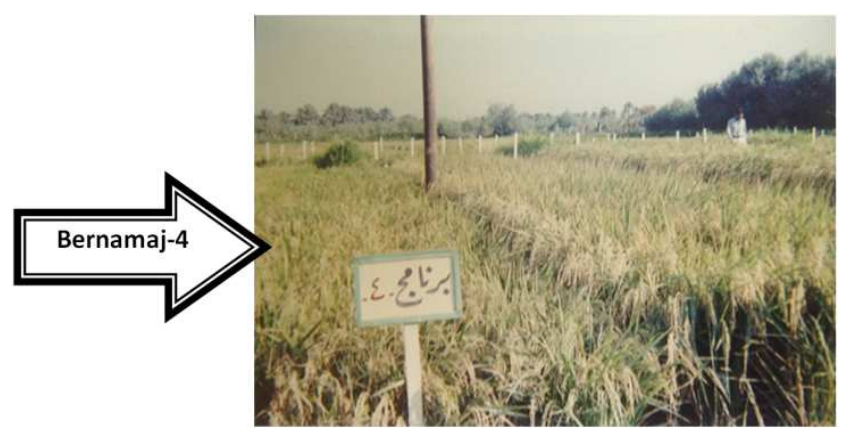

Fig. 4. Short duration variety (Bernamaj-4).

Table (2). Grain yield (GY) t.hat, Growth Duration GD (day) and Plant Height $(\mathrm{PH}) \mathrm{cm}$. (average of 5 years).

\begin{tabular}{llll}
\hline Variety & GY & GD & PH \\
\hline Bernamage-4 & 8.5 & 136 & 86 \\
Anber-33 & 3.2 & 151 & 128 \\
NNGING 57161 & 8.0 & 135 & 85 \\
PK330-1202-6 & 8.2 & 139 & 89 \\
RP2235-48-54-6 & 8.3 & 126 & 88 \\
\hline
\end{tabular}

\subsection{Accurate Timing of Agrochemical Application for Barley and Wheat Crops}

From germination until harvest the plant develops through an orderly series of phases (Kirby and Appleyard, 1984). The timing of these phases depends on the environment and variety, and cannot be predicted with precision. Only direct observation of the shoot apex or developing ear of a plant allows precise identification of the developmental stage. Therefore, an understanding of cereal plant development can give extra insight into other aspects of crop production especially, the application of agrochemicals (e.g. nitrogen fertilizer, plant growth regulators ... etc.) to the cereal crops to increase their grain yield. For nitrogen fertilizer, there is now much interest in the possibility that nitrogen could be used more efficiently if applications were timed on the basis of plant developmental stage. Based on this concept, a two year field trial using widely grown barley varieties, Arivate (Hordeum vulgare L. six - rowed barley) and clipper (Hordeum distichum L. - two - rowed barley was conducted during 1992/1993 and 1993/1994 at the experimental farm of the college of Agriculture at Abu-Ghraib, Iraq (Jaddoa, 1997). Applications of nitrogen fertilizer were timed to coincide with double ridges, maximum spikelet number, and booting stages (Fig. 5). compared with the traditional top-dressing of nitrogen which was based on calendar date i.e. 45 days from sowing.
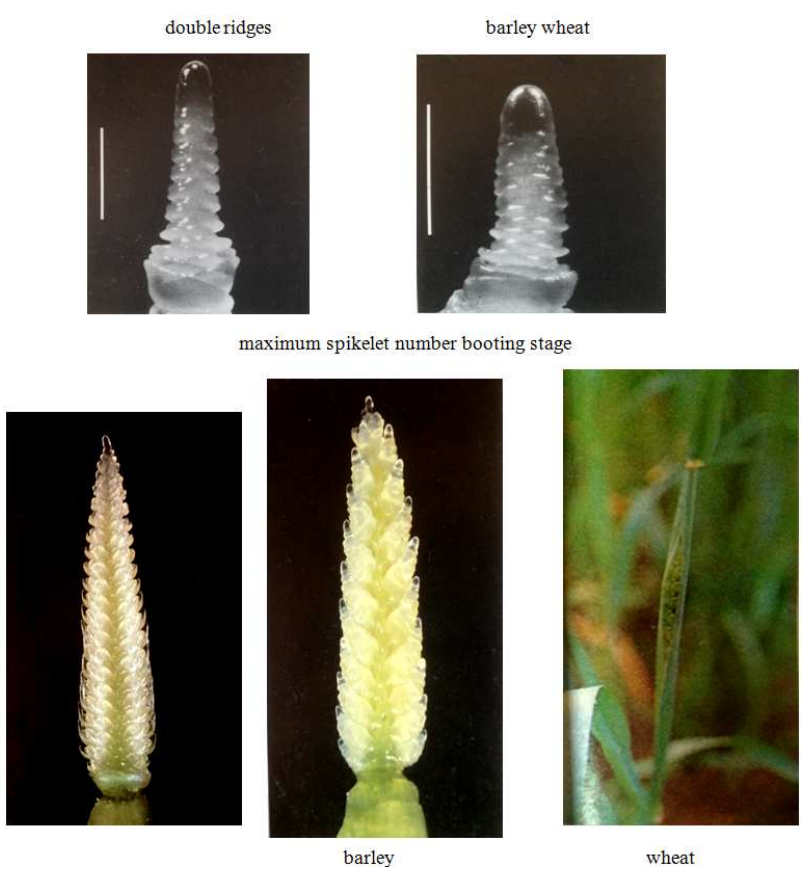

Fig. 5. Critical growth stages of nitrogen application.

The idea of shifting from calendar date criterion to the apex development is based on the fact that barley grain yield can be divided into several components. These components are dependent upon processes controlling apical development and grain filling (Ma and Smith, 1991). In this two-year field trial, nitrogen fertilizer as urea $46 \%$ nitrogen was splitted two or three times. All split treatments increased barley grain yield. Three applications showed the highest increase, 39.6\%. The increased grain yield was due to increased two components, ear number and 1000 kernel weight and, more interestingly, improved harvest index.

This result indicates clearly that timing of the application is equally if not more important than the amount of used nitrogen. In wheat, similar findings were obtained in large scale area (10 ha) south of Baghdad - Wasit province private farm by application of the recommended nitrogen fertilizer at the same developmental stages. There was $22 \%$ increase in the grain yield due to increased ear number and grain number compared with the calendar method of application. Besides, no lodging occurred in the area fertilized by using developmental stages criterion with totally lodged area of control plants.

\section{References}

[1] Al-Hassan, M.F.H. 2007. Tillering pattern and capacity of five wheat cultivars (Triticum aestivum L.) as influenced by sowing date and its relationship to grain yield and its components. M.Sc. Thesis, College of Agriculture, University of Baghdad (In Arabic). 
[2] Al-Hassan, M.F.H. 2011. Understanding of Tillering in Different Wheat Cultivars As Influenced By Seeding Rate and Nitrogen Levels and Its Relationship to Grain Yield and Its Components. Ph. D. Thesis, College of Agriculture, University of Baghdad (In Arabic).

[3] Alireza EIVAZI. 2012. Induction of drought tolerance with seed priming in wheat cultivars (Triticum aestivum L.). Acta agriculturae Slovenica, 99 -1, 21-29.

[4] Al-Mashhadani, A.S.A. 2003. Effect of Irrigation Method and Nitrogen Fertilization On Growth and Yield of Rice (Oryza sativa L.). M.Sc. Thesis, College of Agriculture, University of Baghdad (In Arabic).

[5] Al-Selawy, R.L.A. 2011. Response of Growth and Yield of Some Rice Cultivars to the Seed Enhancement. Ph. D. Thesis, College of Agriculture, University of Baghdad (In Arabic).

[6] Baqir, H.A.R. 2011. Relationship between Sowing Depth, Coleoptile Length, Field Emergence and Yield of Six wheat Cultivars. M.Sc. Thesis, College of Agriculture, University of Baghdad (In Arabic).

[7] Bradford, K.J. 1986. Manipulation of seed water relation via osmotic priming to improve germination under stress conditions. Hort. Sci. 21, 1105-1112.

[8] Bray C.M., P.A. Davision, M. Ashraf, and R.M. Taylor. 1989. Biochemical changes during osmopriming of leak seeds. Ann. Bot. 6, 185-193.

[9] Brockehurst, P.A., and J. Dearman. 2008. Interaction between seed priming treatments and nine seed lots of carrot, celery and onion 11. Seedling emergence and plant growth. Ann. Appl. Biol. 102, 583-593.

[10] Brocklehurst, P.A., J. Dearman, and R.L.K. Drew. 1984. Effect of osmotic priming on seed germination and seedling growth in leak. Sci. Hort., 24: 201-210.

[11] Cheyad, S.H. 2008. Effect of Gibberellic Acid on Viability and Seed Vigour of Sorghum (Sorghum bicolor L.) Meonch) Resulted From Different Plant Population. M.Sc. Thesis, College of Agriculture, University of Baghdad (In Arabic).

[12] Farooq, M., M. Irfan, T. Aziz, L. Ahmad and S.A. Cheema. 2013. Seed Priming with Ascorbic Acid Improves Drought Resistance of Wheat. J. Agron. And Crop Sci. 199, 12-22.
[13] Farooq, M., S.M.A. Basra, A. Wahid, A. Khaliq and N. Kobayashi. 2009. Rice seed invigoration: A review. In E. Lighthouse, ed. Organic Farming, Pest Control and Remediation of soil pollutants, pp. 137-175. Springer, the Netherlands.

[14] Farooq, M., S.M.A. Basra, M. Khalid, R. Tabassum, and T. Mehmood. 2006. Nutrient homeostasis, metabolism of reserves and seedling vigor as affected by seed priming in coarse rice. Can. J. Bot. 84, 1196-1202.

[15] IRRI. 1994 - 1995. Water: A looming Crisis. IRRI. International Rice Research Institute. Philippines.

[16] Jaddoa, K.A. 1997. Accurate Timing of Nitrogen Can Increase Barley Grain Yield. Haddad, Nasri, Richard Tutwiler and Euan Thomson (eds.). Improvement of Crop - livestock integration systems in West Asia and North Africa. Proceedings of the Regional Symposium On Integrated Crop - Livestock Systems In the Dry Areas of West Asia and North Africa, 6-8 November 1995, Amman, Jordan, ICARDA, Aleppo, Syria xi $+572+40$ pp

[17] Kaya, M.D., G. Okcub; M. Ataka, Y. Cikihe, and O. Kolsaricia. 2006. Seed treatments to overcome salt and drought stress during germination in sunflower (Helianthus annuus L.). Eur. J. Agron. 24, 291-295.

[18] Kirby, E.J.M. and M. Appleyard. 1984. Cereal Development Guide, $2^{\text {nd }}$ Edition. National Agricultural Centre. Arable Unit. Stoneleigh - Warwickshire, England.

[19] Ma, B.I. and D.L. Smith. 1991. Apical development of spring barley in relation to Chlormequat and Ethephon. Agron. J. 83: 270-274.

[20] Salih, R.O., K.A. Jaddoa, K.A. Hamed and G.H. Tawfeek. 2007. The Influence of Sprinkler Irrigation On Growth and Productivity of Three Varieties of Rice. Iraqi J. Agric. (special issue), Vol. 12, No. 3.

[21] Salih, R.O., K.A. Jaddoa, K.A. Hamed. 1999. Water use efficiency under intermittent irrigation for rice (Oryza sativa L.) in Iraq. International conference on water resources management, use and policy in dry areas. 1-3 December 1999. Amman, Jordan. 